\title{
A Comparative Analysis of the Flow Properties between Two Alumina-Based Dry Powders
}

\author{
Milene Minniti de Campos and Maria do Carmo Ferreira \\ Chemical Engineering Department, Federal University of São Carlos, 13565-905 São Carlos, SP, Brazil \\ Correspondence should be addressed to Maria do Carmo Ferreira; mariaf@ufscar.br
}

Received 17 June 2013; Revised 5 October 2013; Accepted 19 October 2013

Academic Editor: Dachamir Hotza

Copyright (c) 2013 M. M. de Campos and M. do Carmo Ferreira. This is an open access article distributed under the Creative Commons Attribution License, which permits unrestricted use, distribution, and reproduction in any medium, provided the original work is properly cited.

\begin{abstract}
We measured and compared the flow properties of two alumina-based powders. The alumina powder (AP) is irregularly shaped and has a smooth surface and moisture content of $0.16 \%$ (d.b.), and the ceramic powder (CP), obtained after atomization in a spray dryer, is spherical and has a rough surface and moisture content of $1.07 \%$. We measured the Hausner ratio (HR), the static angle of repose (AoR), the flow index (FI), the angle of internal friction, and the wall's friction angle. The properties measured using aerated techniques (AoR and HR) demonstrated that AP presents true cohesiveness (and therefore a difficult flow), while CP presents some cohesiveness and its flow might be classified as half way between difficult and easy flow. Their FI values, which were obtained using a nonaerated technique, enable us to classify the alumina as cohesive and the ceramic powder as an easy-flow powder. The large mean diameter and morphological characteristics of CP reduce interparticle forces and improve flowability, in spite of the higher moisture content of their granules. The angles of internal friction and of wall friction were not significantly different when comparing the two powders.
\end{abstract}

\section{Introduction}

Alumina-based ceramic powders can be used in a variety of industries such as aerospace, automotive, medical, chemical, electronics, and environmental technologies because these powders can be applied in manufacturing cutting tools, car parts, dentistry, heat exchangers, filters, and refractory tiles [1-3]. The flow of powder during the manufacturing process prescribes the quality of the product in terms of homogeneity and content uniformity. It can also affect its manufacturing efficiency. It is well known that the size distribution of the particles, together with other parameters, such as shape, roughness, density, hardness, and moisture content, have a large impact on the local structure of a particulate system and their flow properties [4-6].

The ability of powder to flow depends on a combination of the physical properties and on the equipment used for handling, storing, or processing it. Given the number of variables and complex phenomena involved, it is impossible to use basic particle/silo properties to predict the flow's behavior of bulk powders using theoretical models based on powder mechanics. Flowability indexes can be determined experimentally using different tests, but, so far, none have been universally accepted as being both reliable and easy to use. A test that has widespread use is based on measuring the shear force required to overcome the cohesive strength of the powder at various vertical loads, following a mathematical method developed by Jenike [7] to design storage hoppers. The flow property measured based on this method is the flow function, a relationship between the cohesive strength of the powder as a function of the consolidating pressure [8]. The flow index (FI) is calculated either as the inverse of the flow function slope [8] or as the inverse of the slope of a line cutting the flow function at a particular point of major consolidation stress and passing through the origin of coordinates [9]. These curves of cohesive strength versus consolidating pressure are measured in direct or annular shear cells, according to detailed procedures described by the ASTM standards D6128-06 and D6773-08, respectively, [10, 11]. Solid theoretical background guarantees the reliability of this test as a quantitative indicator of the powder's flowability. In addition, data obtained by shear testers may provide further information 
about flow properties, such as the angle of internal friction and the angle of wall friction. One disadvantage is that operating direct shear cells requires skilled technicians. The annular model $[12,13]$ favors automation and reduces dependence on the operator's capabilities. However, the high costs of the equipment and the time involved in the tests remain as drawbacks for the widespread use of this method. In some cases, such as when online information on powder flow behavior is necessary, faster methods must be used.

Simpler tests based on the measurements of tapped bulk density and aerated bulk density $[5,14]$ can be used as alternative options. The aerated bulk density of a powder is determined by pouring the powder into a container under the effect of gravity so it settles. The tapped bulk density is obtained by tapping the container with the aerated sample. Two indexes can be determined based on these bulk densities. The ratio of the tapped to the aerated bulk density is called the Hausner ratio (HR) [14]. The higher this ratio, the greater the powder's cohesiveness, and the flow is expected to be more difficult to occur. Values higher than 1.4 are indicative of cohesive material, and values below 1.25 are indicative of an easy flow. The Carr index is preferred in pharmaceutical applications; it is defined as $100(1-1 / \mathrm{IH})$ [15]. These indexes have been empirically established. Because the data may have been obtained using nonstandard procedures for the tests and sample preparation, this published data is not always comparable. However, they are used widely because the equipment required to perform the analysis is cheap and the technique used is easy to learn.

The angle of repose is another quick test for monitoring the powder's flow and obtaining relative measures of flowability. It can be determined by pouring the powder into a funnel which is held at a fixed height above a flat base and measuring the angle formed by the powder's conical heap with a horizontal surface. Angles of repose under $30^{\circ}$ point to powders with good flowability, $30^{\circ}-45^{\circ}$ show some cohesiveness, $45^{\circ}-55^{\circ}$ show true cohesiveness, and anything above $55^{\circ}$ is considered as having very high cohesiveness and limited flowability [16]. Geldart et al. [16] claimed that the AoR may meet the industrial and academic needs for a simple and quick test that can disclose changes in the flow properties of powders as they pass through the processing and handling equipment and proposed a design of a device capable of providing robust and reliable measurements for different types of powders. The unsatisfactory comparison of data obtained by different methodologies is a limiting aspect, as in bulk densities.

Jenike's test uses a nonaerated technique, as the powder is subjected to high intensity external loads to simulate the storage conditions. HR and AoR are classified as aerated techniques, in which the powders are subjected to either none or low intensity external loads [5]. Even though the definition of flowability is not precise and the flow properties are impacted by a large number of variables, some authors suggest that considering all possible test values could be a reasonable approach to address the complexity of this problem [17].

The goal of this research is to compare five measured flow properties of two commercial alumina-based powders that have different particle size distributions and morphologies.
We analyzed two powders, high purity alumina with $99.5 \%$ of $\mathrm{AlO}_{3}$, and a ceramic powder obtained after spray drying a stable suspension of alumina. We measured the loose and tapped bulk densities, the Hausner ratio (HR), THE static angle of repose (AoR), THE flow index (FI), the internal friction angle, and the wall friction angle.

\section{Materials and Methods}

2.1. Powders. Alumina powder (AP) used in the tests was manufactured by ALCOA (Brazil) and contained 99.5\% of $\mathrm{Al}_{2} \mathrm{O}_{3}$. The second powder was obtained after drying the suspension of alumina and will be referred to here as a "ceramic powder" (CP). The solid content of aqueous dispersion was $95.2 \%$ of aluminum oxide and $4.8 \%$ of other oxides (silicium, sodium, magnesium, and calcium oxides). This suspension contained also $2 \%$ of organic additives, namely, polyvinyl alcohol (PVA1), ammonium polyacrylate, and stearic acid, added to act as dispersants and lubricants. Both the powder and the suspension were acquired from ENGECER, São Carlos, SP, Brazil. The suspension was dried in a spray dryer Büchi, model 190, at a volumetric flow rate of $0.3 \mathrm{~mL} / \mathrm{s}$, with atomization pressure of 2 bars and inlet air temperature of $165 \pm 5^{\circ} \mathrm{C}$.

Powder distribution sizes were measured by a static laser light scattering technique (MAF 5001 Malvern, Malvern Instruments Ltd.) after wet dispersion (alumina) and dry dispersion (ceramic powder). Three measurements were performed for alumina powder and ten measurements for ceramic powder and the results reproduced successfully. Micrographs of the powders were obtained using an electronic scan microscopy (MEV INSPECT S50, FEI) in order to access the particle's morphology. The moisture content of the powders was measured by the gravimetric method, according to the standards from AOAC International [18] by keeping samples in a forced convection oven at $(105 \pm 3)^{\circ} \mathrm{C}$ and measuring the difference between final and initial masses. Particle densities were measured using a helium pycnometer (Accupyc 1330, Micromertitics).

2.2. Aerated and Tapped Bulk Densities. Aerated bulk density was obtained by pouring the powder into a funnel placed at the top of a calibrated glass vessel with a total volume of $250 \mathrm{~mL}$ and a diameter of $22 \mathrm{~mm}$. A mass of powder was weighed using an analytical scale and added to the vessel, and the volume of powder was measured. The tapped bulk density was obtained by clamping the glass vessel into the device illustrated in Figure 1 and performing manual tapping.

The tapping procedure consisted of lifting the vessel up until reaching the horizontal bar located at a distance of $3 \mathrm{~cm}$ from the base and then dropping it. Throughout tapping, powder was compacted, and the volume of powder into the recipient went down and was recorded after each tapping. This procedure was repeated until no further changes in the volume of the powder could be identified. The Hausner ratio (HR) was estimated using the following definition:

$$
\mathrm{HR}=\frac{\rho_{\mathrm{cb}}}{\rho_{\mathrm{lb}}},
$$




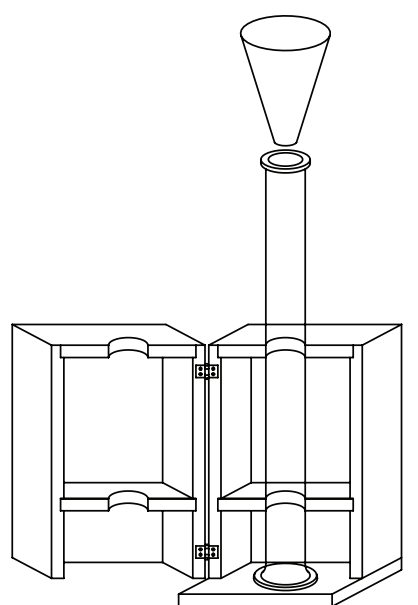

FIGURE 1: Device used for measuring powder tapped bulk density.

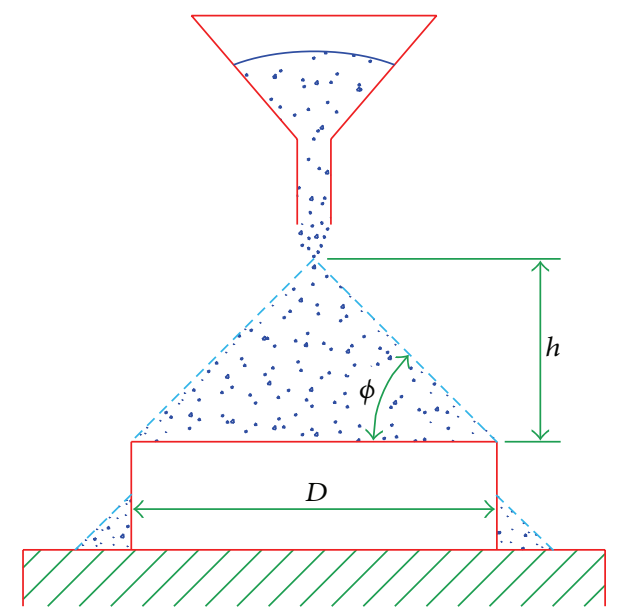

Figure 2: Measurement of angle of repose of powders.

where $\rho_{\mathrm{cb}}$ and $\rho_{\mathrm{lb}}$ are the tapped and loose bulk densities, respectively.

2.3. Angle of Repose. The AoR was measured using a funnel with an orifice of $20 \mathrm{~mm}$ diameter, whose wall formed an angle of $65^{\circ}$ with a horizontal plane. Each test was repeated at least three times.

The funnel was held at a height of $9 \mathrm{~cm}$ above the flat base while the powder was poured through it, as we show in Figure 2. The diameter and the height of the powder's conical heap formed at the surface were measured and the AoR was calculated using

$$
\emptyset=\operatorname{arctg}\left(\frac{h}{D / 2}\right)
$$

where $h$ is the high of conical heap and $D$ is the diameter, according to Figure 2.

2.4. Flow Function and Effective Angle of Internal Friction. A direct shear cell TSG 70-140-AVT (available at the laboratory of Wood and Timber Structures, São Paulo University, São
Carlos, SP, Brazil) was used to measure the flow's function and the effective angle of internal friction. The cell used had an internal diameter of $93 \mathrm{~mm}$ and the shear rate ranged from 1 to $3 \mathrm{~mm} / \mathrm{min}$. The procedure used to measure the instantaneous flow function was recommended by the Standard Test Method for Shear Testing of Bulk Solids Using the Jenike Shear Cell [9]. It is based on plotting the failure of shear stress versus normal stress, known as yield locus. To construct a yield locus, a selected powder is consolidated under a given consolidating stress, in a step known as preshear. After preshearing, the powder is subjected to shearing, where the shear stresses required to cause the powder to fail under different normal stresses are measured [8]. For each powder, three different levels of consolidating stress were applied $(100,70$, and $50 \mathrm{~N})$. These values were chosen following the recommendations of the ASTM: D6128-06 [9], based on the bulk properties of the powders. For each level of consolidating stress, the failure shear stress under three different normal stresses, below the consolidating stress was measured, and three yield loci were obtained. These data were combined with Mohr stress circles to determine parameters such as the cohesion of the powder, the tensile stress, and the shear index (for a detailed description of the procedure to fit the yield locus and fitting parameters; see Fitzpatrick et al. [8]). In this study, the Mohr stress circles tangent to the yield locus were calculated using software developed by Diniz [19]. The unconfined yield strength (UYS) and the major consolidating stress (MCS) can be estimated from each yield locus. A flow function is a plot of UYS versus MCS, and the flow index is defined as the inverse of the slope of a flow function linear fitted curve. The wall yield locus of powders was measured using Jenike's cell described above in which the cylindrical base of the cell was replaced by a flat plate of galvanized iron. The wall yield locus was obtained by measuring the horizontal stress required to make the powder fail at the following normal stresses: 9.0, $7.5,6.0,4.6,3.1$, and $1.6 \mathrm{kPa}$. The procedure used was the one recommended by the ASTM, using Jenike's shear cell. The angle of wall friction $\left(\varphi_{w}\right)$ reported is the angle formed with the horizontal axis by a line drawn from the origin to a point on the wall's yield locus with a normal stress of $9.0 \mathrm{kPa}$. All measurements were carried out at ambient temperature and relative moisture ranging from 40 to $55 \%$.

\section{Results and Discussion}

3.1. Physical Properties of the Powders. The powders size distributions, obtained from the average of measurements can be seen in Figure 3.

The particle size distributions in Figure 3 show a broad range of particle sizes. Alumina shows a bimodal distribution, with sizes from 0.1 to $100 \mu \mathrm{m}$ and two particle concentration peaks, a major one at $d_{p}=9.0 \mu \mathrm{m}$ and a minor one at $d_{p}=$ $0.5 \mu \mathrm{m}$. A mixture of particles of different sizes is common in powders meant for applications into the ceramic field. They are used to obtain denser packed-beds and to improve the mechanical resistance of manufactured materials [20]. The ceramic powder shows a unsymmetrical and wide size distribution, with sizes from 1 to $1000 \mu \mathrm{m}$. The ceramic powder shows a peak at $d_{p}=15 \mu \mathrm{m}$ and a significant fraction of 


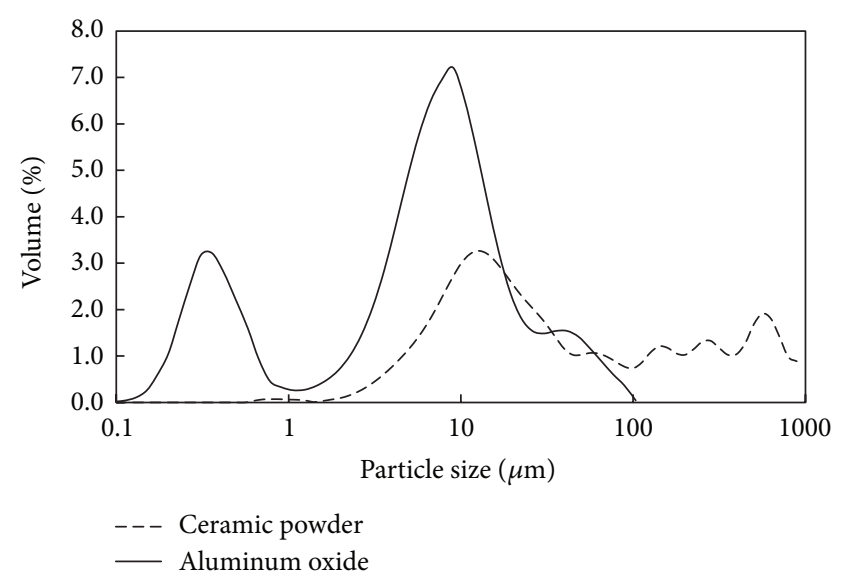

Figure 3: Particle size distribution of the powders.

particles with sizes from $100 \mu \mathrm{m}$ to $1000 \mu \mathrm{m}$. These coarse particles are probably formed due spray drying, where primary particles of smaller size agglomerate and generate ceramic granules of larger size. The mean Sauter diameters for alumina and ceramic powder are equal to $d_{p S}=1.25 \pm$ $0.01 \mu \mathrm{m}$ and $d_{p S}=679 \pm 29 \mu \mathrm{m}$, respectively.

The main physical properties of the particles and the powders' moisture content are shown in Table 1. Based on the particle's density and mean diameter, these powders belong to group $C$ in Geldart's classification [21], characterized as being cohesive with nonfree flow and difficult to fluidize.

Micrographs of the powders are shown in Figure 4. As noted in the graphs, alumina has particles with irregular shape and angular morphology, with a smooth surface, while ceramic powder has particles with spherical shapes and a rough surface. The differences in their morphologies are due to the atomization in their spray drying and to the presence of additives in the original ceramic suspension.

3.2. Bulk Densities, Hausner Ratio, and Angle of Repose. Data of bulk density as a function of number of tappings $(N)$ are shown in Figure 5. The loose bulk densities are the values measured at $N=0$, which were equal to $676 \mathrm{~kg} / \mathrm{m}^{3}$ and $826 \mathrm{~kg} / \mathrm{m}^{3}$, respectively, for the alumina and ceramic powder. The loose bulk density's value in the ceramic powder is about $22 \%$ higher than that of alumina, which is expected since initial bulk density increases with mean particle size [22]. This difference is reduced to $7 \%$ at full compaction of the powder, which is reached at $N$ being equal to 350 . The compacted bulk densities were 1,064 for alumina and 1,136 for ceramic powder. Particle size, particle shape, size distribution, surface texture, agglomeration, and cohesion are key factors that affect bulk densities [22]. The powders we analysed are mostly made up of aluminum oxide, with similar particle densities but quite different size distributions (Figure 3), Sauter mean diameters (Table 1), shape, and surface roughness (Figure 4), which may explain the differences in their packing densities.

It can also be observed from Figure 5 that the change in bulk densities is more intense from $N=0$ to 150 , after which their variation becomes gradually less until it reaches a
TABLE 1: Physical properties and moisture content of powders.

\begin{tabular}{lccc}
\hline Powder & $\rho_{p}\left(\mathrm{~kg} / \mathrm{m}^{3}\right)$ & $d_{p S}(\mu \mathrm{m})$ & $X(\%)$ \\
\hline AP & 4,043 & $1.25 \pm 0.01$ & $0.16 \pm 0.04$ \\
CP & 3,883 & $679 \pm 29$ & $1.07 \pm 0.08$ \\
\hline
\end{tabular}

constant value, at $N$ being equal to 350 . The binary distribution size of alumina and the wide size distribution of the ceramic powder, with a mixture of particles of very different sizes, favor this initial compaction because the smaller particles fill in the voids formed among the large ones which is expected to be more intense at the beginning of the tapping process.

The HR calculated in (1) is 1.57 for the alumina powder and 1.38 for ceramic powder. These values prove/show/ demonstrate that the alumina is a cohesive powder (HR over 1.40) and the ceramic powder is moderately cohesive (HR between 1.25 and 1.40). Similar trends are observed in the measured AoR values: $50 \pm 3^{\circ}$ for alumina and $44 \pm 2^{\circ}$ for ceramic powder. The alumina's AoR is characteristic of cohesive behavior, and the ceramic powder's AoR value is at the boundary between cohesive and medium flow behavior. The lower value of the ceramic powder's AoR demonstrates a freer flow of this material when compared to alumina, a behavior that agrees with the predictions of the measured values in $H R$.

3.3. Flow Index, Angle of Internal Friction, and Wall Friction Angle. The flow functions (plots of UYS versus MCS) of both powders are presented in Figure 6.

According to Fitzpatrick et al. [8], the flow indexes may be calculated as the inverse of the flow function slopes. The values obtained by applying this definition are 2.1 for alumina and 3.3 for ceramic powder. Another possible definition is based on the assumption that, in order to compare the flow index of two materials, it has to be estimated at the same consolidation state [9]. By this definition, the flow index should be calculated as the inverse of the slope of a line cutting the flow function at a particular point of major consolidation stress and passing through the origin of coordinates. Considering Figure 6 and setting a value of $25 \mathrm{kPa}$, which is an intermediate value of the three major consolidation stress values obtained, the flow index for the alumina powder is 3.1 and for the ceramic powder is 4.6 . We presented the results using these two definitions since both are reported in the literature, but from here the values obtained according to the second definition will be adopted, since the comparison at a given consolidations stress seems to be more consistent from a physical perspective. The indexes of 3.1 and 4.6 show that alumina might be classified as cohesive, since it is in the range between 2 and 4, while ceramic powder might be considered as an easy flow powder. The alumina powder's FI value obtained here, equal to 3.1, is lower than the value measured by Fatah [4] for alumina, which is 4.2, and suggests a powder with easy flow. The difference in flow behavior may be justified by the greater Sauter mean diameter $(3 \mu \mathrm{m})$ and narrower size distribution $(\mathrm{UI}=2.6)$ of the alumina powder tested by Fatah in comparison to the alumina tested in the present 


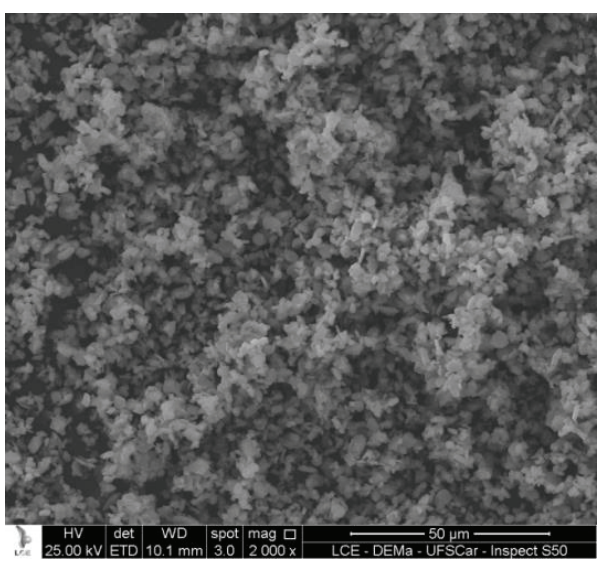

(a)

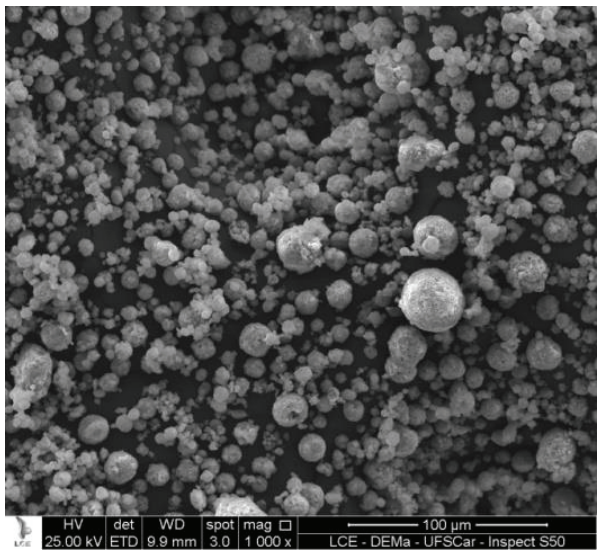

(c)

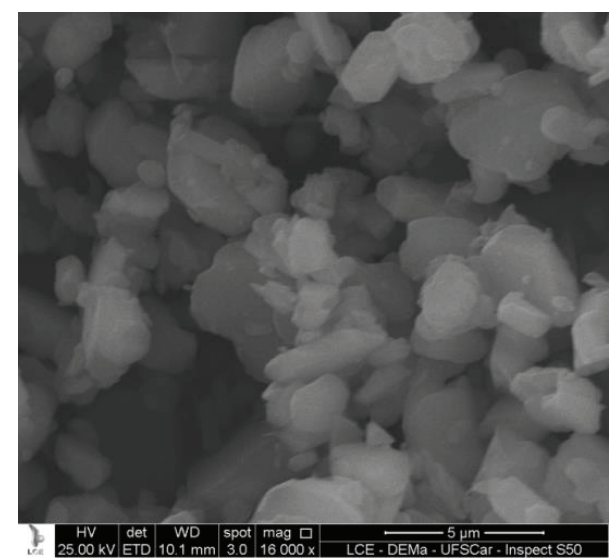

(b)

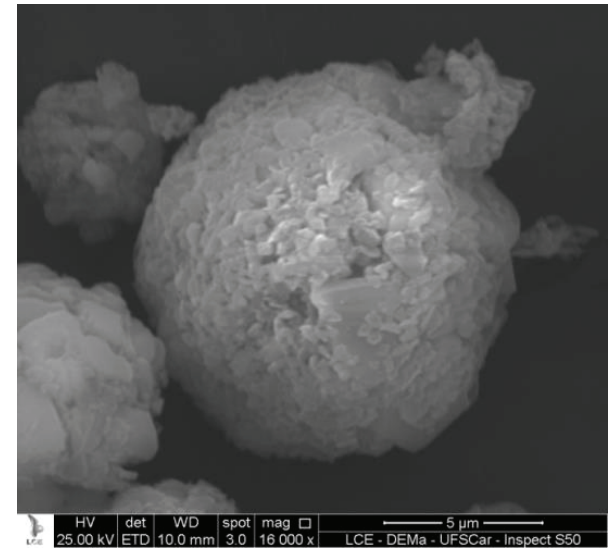

(d)

FIGURE 4: Scanning electron micrographs: (a) AP magnified 2,000x, (b) AP 16,000x, (c) CP 1,000x, (d) CP 16,000x.

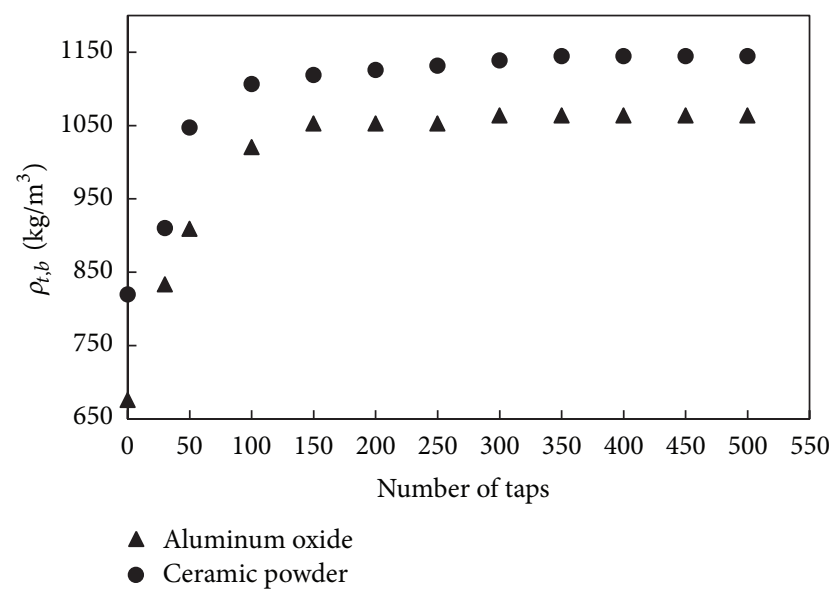

FIGURE 5: Powder bulk density as a function of number of tappings.

study. The binary and nonuniform size distributions, which include particles of diameters below $1 \mu \mathrm{m}$ and up to $100 \mu \mathrm{m}$, and the smaller Sauter diameters of alumina powder tested here are features that contribute to worsening their flowability.

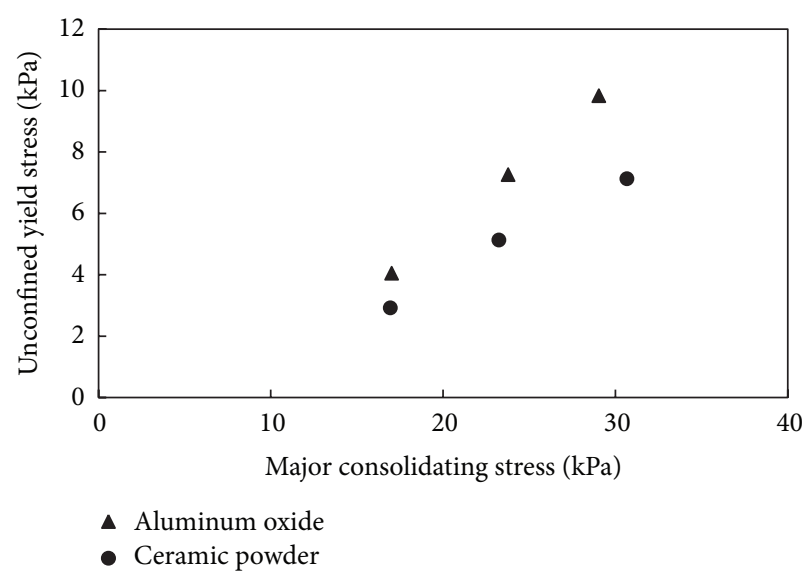

Figure 6: Powder flow functions.

The effective angle of internal friction and angle of wall friction values are used to design hoppers in Jenike's mathematical methods and are related to the failure properties in the materials. The effective angle of internal friction is a measure of interparticle interactions. The measured angles of 
Advances in Materials Science and Engineering

internal friction, equal to $41 \pm 1^{\circ}$ and $41 \pm 2^{\circ}$, are not significantly different among our evaluated powders.

The angle of wall friction represents the adhesive strength of the powder and the silo's or hopper's wall material; the larger the value of the angle is, the more difficult is to move the powder along the wall's surface [8]. The values obtained for alumina and ceramic powder were $28^{\circ}$ and $29^{\circ}$, respectively. Because the interaction between the powder and the wall takes precedence over the interparticle forces, this parameter is not related to the powder flow properties. Fitzpatrick et al. [8] measured the angle of wall friction for 12 different food powders and observed a wide variation among their values, ranging from $12^{\circ}$ to $27^{\circ}$. The authors were unable to establish a correlation between the powder's physical properties and their angle of wall friction. They attributed this difficulty to the increased complexity of having to consider the wall's material properties and how they interact with the powder. The values obtained in this work are close to the top values obtained by Fitzpatrick et al. [8]. High values of angle of wall friction indicate that the flow of powder along the wall of a hopper will be difficult and the minimum hopper's angle has to be increased to assure the mass flow of a powder at its discharge. Mass flow is the preferred mode in most operations because it provides a continuous flow, in an approach known as "first in, first out" where the full hopper's capacity is used [23].

3.4. Influence of Particle Size, Morphology, and Moisture Content. Considerable research has been carried out to study the effect of particle size and shape in the flowability of powders. When two particles come in contact, they are subjected to capillary, electrostatic, and van der Waals forces [24]. For uncharged and dry powders, the first two forces are negligible as compared to the later one, as is the case for the powders analyzed here [24]. To clarify the influence of the interparticle forces on the dynamic behavior of the powders, Fatah [4] compared the magnitude of cohesion forces with the weight of the particles. When the weight of the particles is higher than the interparticle forces, the particles are characterized as having a regular free flow. When it is the other way around, the displacement of a particle onto another particle becomes difficult. The ratio of van der Waals forces to the particle's weight increases as the size of the particles decreases. Therefore, reducing the size of the particles can reduce flowability because the particle's surface area per unit mass decreases and generates a larger surface area for the surface's cohesive forces to interact.

The effect of the particle's morphology on their flow properties is not as clearly understood as their size. The roughness of the surface has a significant effect on the adhesion force, and changing the roughness can change the van der Waals interaction by up to several orders of magnitude [24]. Some researchers have reported that the presence of asperities on surfaces contributes to reducing the intensity of the physical forces because of the reduction of the particle's surface contact [24-26]. The geometry of particles is another factor that affects the flow properties of a powder. Mohammed et al. [5] observed that the irregularities in their shape cause considerable interlocking among the particles and increases
TABLE 2: Measured flow properties of alumina and ceramic powder.

\begin{tabular}{llllll}
\hline Powder & AoR $\left(^{\circ}\right)$ & HR & FI & $\alpha\left(^{\circ}\right)$ & $\varphi_{w}\left(^{\circ}\right)$ \\
\hline AP & $50 \pm 3^{\circ}$ & 1.57 & 3.1 & $41 \pm 1$ & $28 \pm 2$ \\
CP & $44 \pm 2^{\circ}$ & 1.38 & 4.6 & $41 \pm 2$ & $29 \pm 1$ \\
\hline
\end{tabular}

their resistance to flow, while their roundness reduces the interparticle's forces and improves their flow properties.

Powder moisture content usually has a significant impact on powder flowability, as the liquid bridges and capillary forces acting between powder particles lead to reduced flowability [27]. Spray-dried ceramic powder has a moisture content which is 7 times higher than the moisture content of alumina powder. Still, the larger size of ceramic agglomerates and their high sphericity outweigh the moisture effect.

The measured flow properties for alumina and ceramic powder are summarized in Table 2.

The alumina powder has a $13 \%$ higher AoR, $14 \%$ higher $\mathrm{HR}$, and $48 \%$ higher FI than those in the ceramic powder. The angles of internal friction and of wall friction failed to differ significantly. Alumina is classified as difficult to flow and ceramic powder as easy to flow because of their measured flow indexes (FI). The ceramic powder's HR and AoR values are in the limit from "difficult to medium" flow, while alumina's HR and AoR values point out to a "difficult" flow.

Therefore, better flow properties of ceramic powder than those of alumina may be attributed to their different sizes and morphological characteristics. The greater Sauter mean diameter, spherical shapes, and rough surface of the particles in the ceramic powder reduce the intensity of interparticle forces and improve its flow. It is important to note that the increase observed in the flow indexes of ceramic powder compared to those of alumina were similar for the aerated techniques (AoR and HR). The difference in the FI values was much bigger than the differences observed in AoR and HR, suggesting that the effect of different morphological characteristics of the powders on flowability is more significant when large external stresses are applied to the powder. In the case of fine cohesive powders, interparticle attractive forces may increase by several orders of magnitude with an applied external load [28-30]. The only flow parameters that were not sensitive to the particle's morphology were the angles of internal friction and angle of wall friction, which did not differ significantly between the powders. The angle of wall friction is not related to powder flow properties because the interaction between the powder and the wall takes precedence over the interparticle forces.

\section{Conclusions}

This paper presents the measured flow properties of two alumina-based powders with different sizes and morphology. The measured values of aerated flow properties (AoR and HR) showed that alumina powder may be classified as cohesive, while ceramic powder may be classified as having an intermediary flow behavior. The FI values, obtained after powder consolidation, enabled us to classify alumina as cohesive and ceramic powder as an easy-flow substance. 
The cohesive behavior of alumina is consistent with the particles' small size (Sauter diameters of $1.25 \mu \mathrm{m}$ ), irregular shape, and low moisture content. In spite of the higher moisture content of ceramic powder, the greater Sauter diameter $(679 \mu \mathrm{m})$, spherical shape, and rough surface improved the behavior of its flow. The measured angles of internal friction and angle of wall friction were not sensitive to the change in the powder's morphology and did not differ significantly between the two powders.

\section{Acknowledgments}

Financial support by the National Council of Scientific and Technological Development $(\mathrm{CNPq}$, Brazil) and help from the staff at the Laboratory of Wood and Timber Structures (LAMEN), São Paulo University, São Carlos, Brazil in using the Jenike cell are gratefully appreciated.

\section{References}

[1] C. Z. Huang, J. Wang, and X. Ai, "Development of new ceramic cutting tools with alumina coated carbide powders," International Journal of Machine Tools and Manufacture, vol. 40, no. 6, pp. 823-832, 2000.

[2] J. R. Kelly and P. Benetti, "Ceramic materials in dentistry: historical evolution and current practice," Australian Dental Journal, vol. 56, no. 1, pp. 84-96, 2011.

[3] A. Sommers, Q. Wang, X. Han, C. T’Joen, Y. Park, and A. Jacobi, "Ceramics and ceramic matrix composites for heat exchangers in advanced thermal systems-a review," Applied Thermal Engineering, vol. 30, no. 11-12, pp. 1277-1291, 2010.

[4] N. Fatah, "Study and comparison of micronic and nanometric powders: analysis of physical, flow and interparticle properties of powders," Powder Technology, vol. 190, no. 1-2, pp. 41-47, 2009.

[5] S. A. Mohammed, E. C. Abdullah, D. Geldart, and A. A. A. Raman, "Measuring powder flowability with a modified Warren Spring cohesion tester," Particuology, vol. 9, no. 2, pp. 148-154, 2011.

[6] J. J. Fitzpatrick, T. Iqbal, C. Delaney, T. Twomey, and M. K. Keogh, "Effect of powder properties and storage conditions on the flowability of milk powders with different fat contents," Journal of Food Engineering, vol. 64, no. 4, pp. 435-444, 2004.

[7] A. W. Jenike, Storage and Flow of Solids, Bulletin 123 of the University of Utah, vol. 53, no. 26 (Bull 123 of Utah Engineering experiment station), University of Utah, 1964.

[8] J. J. Fitzpatrick, S. A. Barringer, and T. Iqbal, "Flow property measurement of food powders and sensitivity of Jenike's hopper design methodology to the measured values," Journal of Food Engineering, vol. 61, no. 3, pp. 399-405, 2004.

[9] J. L. Amorós, G. Mallol, C. Feliu, and M. J. Orts, "Study of the rheological behaviour of monomodal quartz particle beds under stress. A model for the shear yield functions of powders," Chemical Engineering Science, vol. 66, no. 18, pp. 4070-4077, 2011.

[10] ASTM: D6128-06, "Standard Test Method for Shear Testing of Bulk Solids Using the Jenike Shear Cell," American Society for Testing And Materials, 2011.

[11] ASTM: D6773-08, "Standard Test Method for Shear Testing of Bulk Solids Using the Schulze Ring Shear Tester," American Society for Testing And Materials, 2011.
[12] D. Schulze, "Measuring powder flowability: a comparison of test methods part I," Powder and Bulk Engineering, vol. 10, no. 4, p. $12,1996$.

[13] D. Schulze, "Measuring powder flowability: a comparison of test methods. Part II," Powder and Bulk Engineering, vol. 10, no. 6, pp. 17-28, 1996.

[14] E. C. Abdullah and D. Geldart, "The use of bulk density measurements as flowability indicators," Powder Technology, vol. 102, no. 2, pp. 151-165, 1999.

[15] E. Emery, J. Oliver, T. Pugsley, J. Sharma, and J. Zhou, "Flowability of moist pharmaceutical powders," Powder Technology, vol. 189, no. 3, pp. 409-415, 2009.

[16] D. Geldart, E. C. Abdullah, A. Hassanpour, L. C. Nwoke, and I. Wouters, "Characterization of powder flowability using measurement of angle of repose," China Particuology, vol. 4, pp. 104107, 2006.

[17] J. K. Prescott and R. A. Barnum, "On powder flowability," Pharmaceutical Technology, vol. 24, no. 10, pp. 60-236, 2000.

[18] AOAC, Official Methods of Analysis, Association of Official Analytical Chemists, Washington, DC, USA, 1980.

[19] L. G. Diniz, "Development of a program to calculate the properties of products stored in hoppers," Tech. Rep., Department of Structural Engineering, São Carlos School of Engineering, University of São Paulo State, São Carlos, Brazil, 2010, (Portuguese).

[20] A. P. Silva, A. M. Segadães, and T. C. Devezas, "Application of statistical methods to optimize packing density of alumina powder size distributions," Cerâmica, vol. 50, pp. 345-354, 2004 (Portuguese).

[21] D. Geldart, “Types of gas fluidization," Powder Technology, vol. 7, no. 5, pp. 285-292, 1973.

[22] G. Mallol, J. L. Amorós, M. J. Orts, and D. Llorens, "Densification of monomodal quartz particle beds by tapping," Chemical Engineering Science, vol. 63, no. 22, pp. 5447-5456, 2008.

[23] C. R. Woodcock and J. S. Mason, Bulk Solids Handling: An Introduction to the Practice and Technology, Leonard Hill, Glasgow, UK, 1987.

[24] A. Castellanos, "The relationship between attractive interparticle forces and bulk behaviour in dry and uncharged fine powders," Advances in Physics, vol. 54, no. 4, pp. 263-276, 2005.

[25] H. Zhou, M. Götzinger, and W. Peukert, "The influence of particle charge and roughness on particle-substrate adhesion," Powder Technology, vol. 135-136, pp. 82-91, 2003.

[26] H. Rumph, Particle Technology, Chapman and Hall, London, UK, 1990.

[27] E. Scoville and M. Peleg, "Evaluation of the effect of liquid bridges on the bulk properties of model powers," Journal of Food Science, vol. 46, pp. 174-177, 1981.

[28] J. M. Valverde, A. Ramos, A. Castellanos, and P. K. Watson, "The tensile strength of cohesive powders and its relationship to consolidation, free volume and cohesivity," Powder Technology, vol. 97, no. 3, pp. 237-245, 1998.

[29] P. K. Watson, J. M. Valverde, and A. Castellanos, "The tensile strength and free volume of cohesive powders compressed by gas flow," Powder Technology, vol. 115, no. 1, pp. 45-50, 2001.

[30] J. M. Valverde, A. Castellanos, and P. K. Watson, "The effect of particle size on interparticle adhesive forces for small loads," Powder Technology, vol. 118, no. 3, pp. 236-241, 2001. 

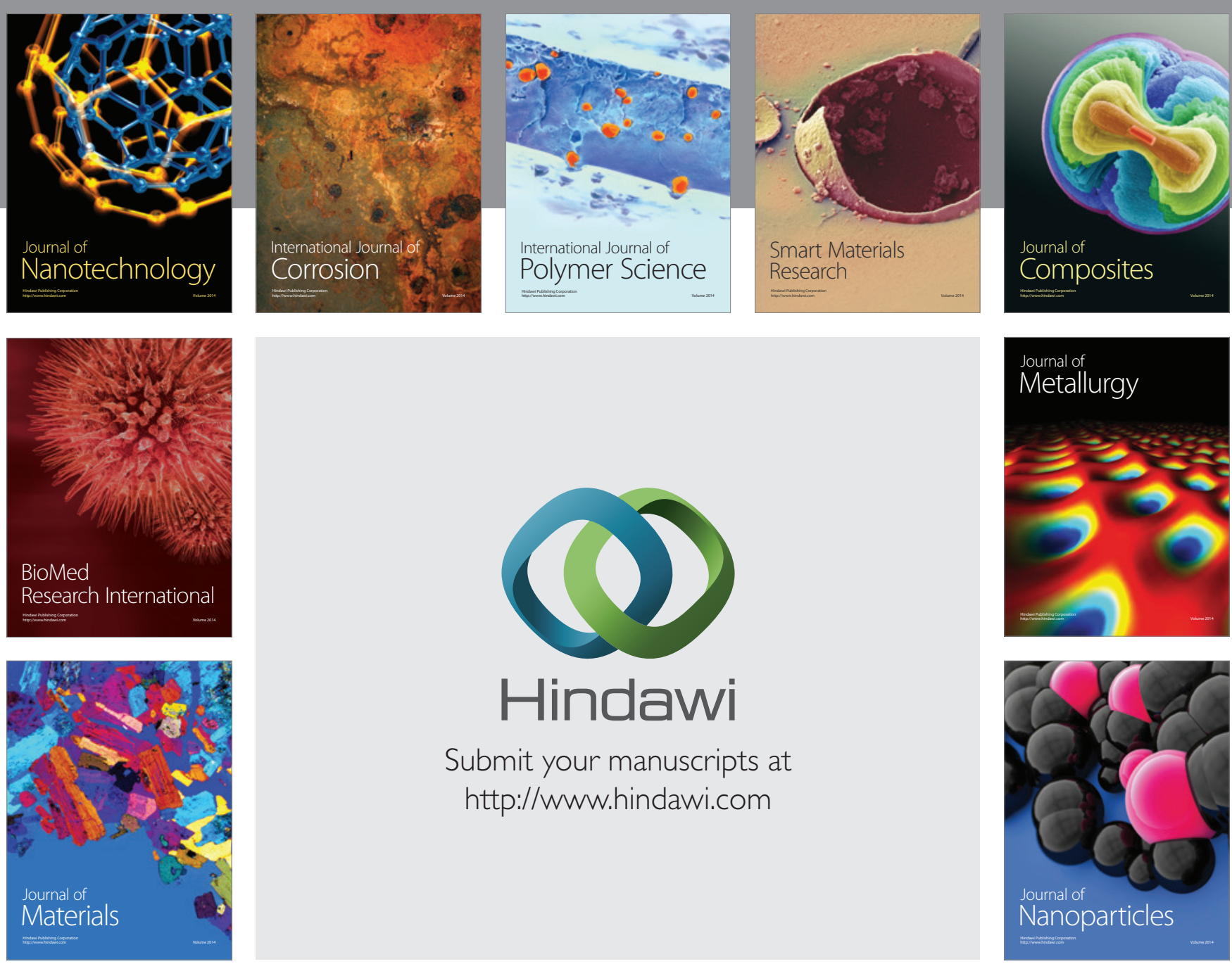

Submit your manuscripts at http://www.hindawi.com
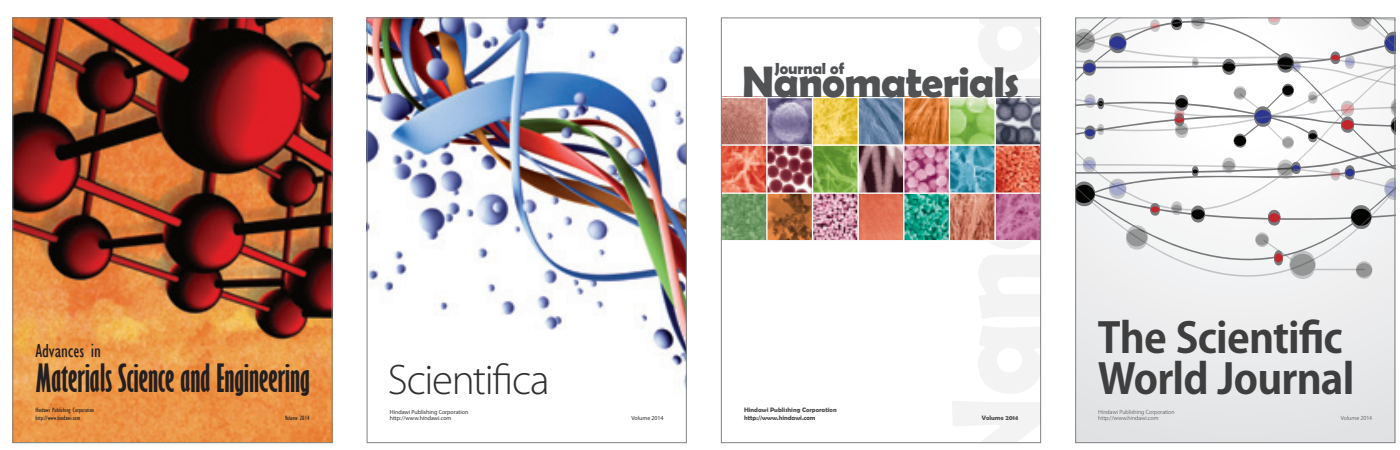

\section{The Scientific World Journal}
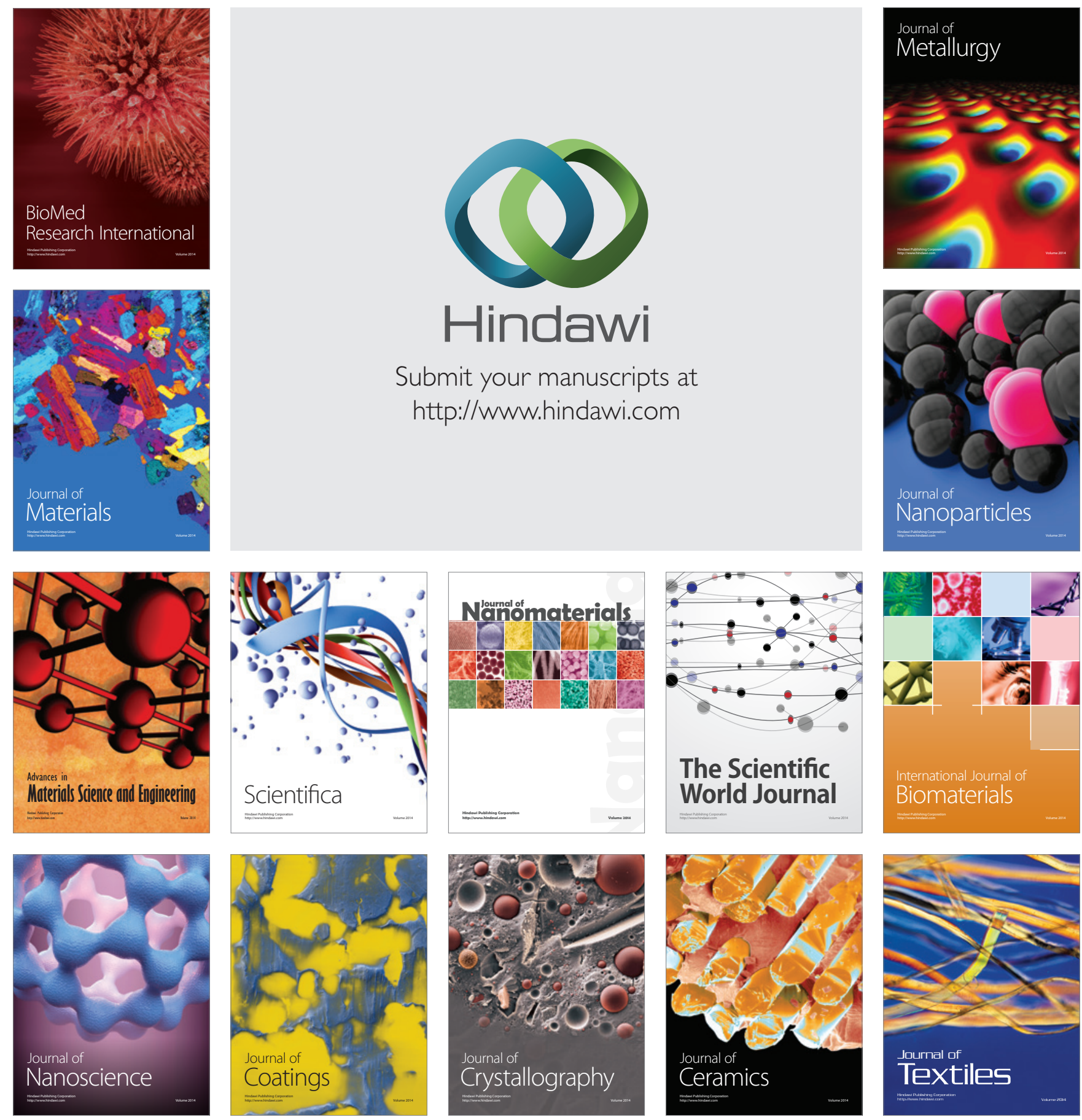